\title{
FEM Analysis of the Multi-Wedge Helical Rolling Process for a Workholding Bolt
}

\author{
Zbigniew Pater ${ }^{1, a}$ \\ ${ }^{1}$ Lublin University of Technology, Faculty of Mechanical Engineering, 36 Nadbystrzycka Str, Lublin, Poland
}

\begin{abstract}
This paper presents the results of a numerical analysis of a helical rolling process for producing a $25 \mathrm{~mm}$ diameter workholding bolt using multi-wedge helical tools. The numerical modeling was performed by the finite element method (FEM) using the commercial simulation software Simufact.Forming v. 12. The modeling was performed in a three-dimensional state of strain and included a full thermal analysis. As a result, the changes in workpiece shape as well as the distributions of strains, temperature, damage, loads and torque were determined. The numerical results confirm that workholding bolts can be produced by multi-wedge helical rolling.
\end{abstract}

\section{Introduction}

Metal forming methods are widely employed for producing axi-symmetric parts that are used in the automotive, aircraft, machine building and mining industries as well as in other branches of economy. Axisymmetric parts can be produced by methods such as die forging, rotary forging, machine forging, extrusion, forge rolling and others $[1,2]$. Despite the availability of the numerous methods for producing axi-symmetric parts, research has been continued to develop new methods for forming these parts. The focus is here on developing methods which will help reduce material and energy consumption of the manufacturing process, as well as ensuring at the same time increased efficiency. One of these new methods is helical wedge rolling (HWR).

The assumptions of the HWR process were developed at the Lublin University of Technology as part of the research and development work on new highly efficient methods for producing balls for ball mills [3-4]. In the research, it was assumed that balls can be formed by wedges that are helically wound (in a single- or multi-coil manner) on the roll face. The numerical results and experimental tests confirmed the correctness of this solution [5-8]. The development of the HWR method involved the design of single-coil tools for producing such parts as stepped shafts $[9,10]$, bodies of rotary cutters [11] and workholding bolts [12]. The developed solutions were verified by numerical simulation.

This paper describes a new way of forming parts such as a workholding bolt (Fig. 1). The method is based on the helical wedge rolling (HWR) process which is performed using rolls with three helically wound forming wedges. Named as multi-wedge helical rolling (MWHR), this process is characterized by very high efficiency and high values of force parameters. The proposed solution

\footnotetext{
${ }^{\text {a }}$ Corresponding author: z.pater@pollub.pl
}

was verified in a numerical simulation performed using the finite element method-based simulation program Simufact.Forming v.12.

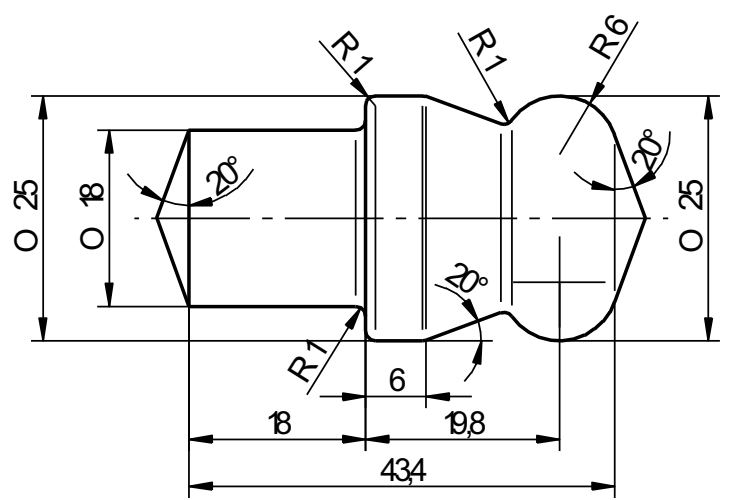

Figure 1. Workholding bolt investigated by numerical analysis

\section{Application of FEM for analysis of helical rolling processes}

The MWHR process is a variant of helical rolling. It is performed using rolls with helically wound wedges on their perimeter. The first studies on numerical modeling of helical rolling were conducted in the 1990s; they concerned a piercing process for thick-walled tubes and were based on two-dimensional FEM models [13]. However, given the nature of metal flow in these processes, they should be simulated in a threedimensional (3D) state of strain. The first attempts at 3D modeling of piercing processes were made by Pietisch and Thieren [14], Ceretti et al. [15], and Komori [16]. The numerical models developed by the above authors included numerous simplifications, for instance they did not take into account thermal phenomena in the material. 

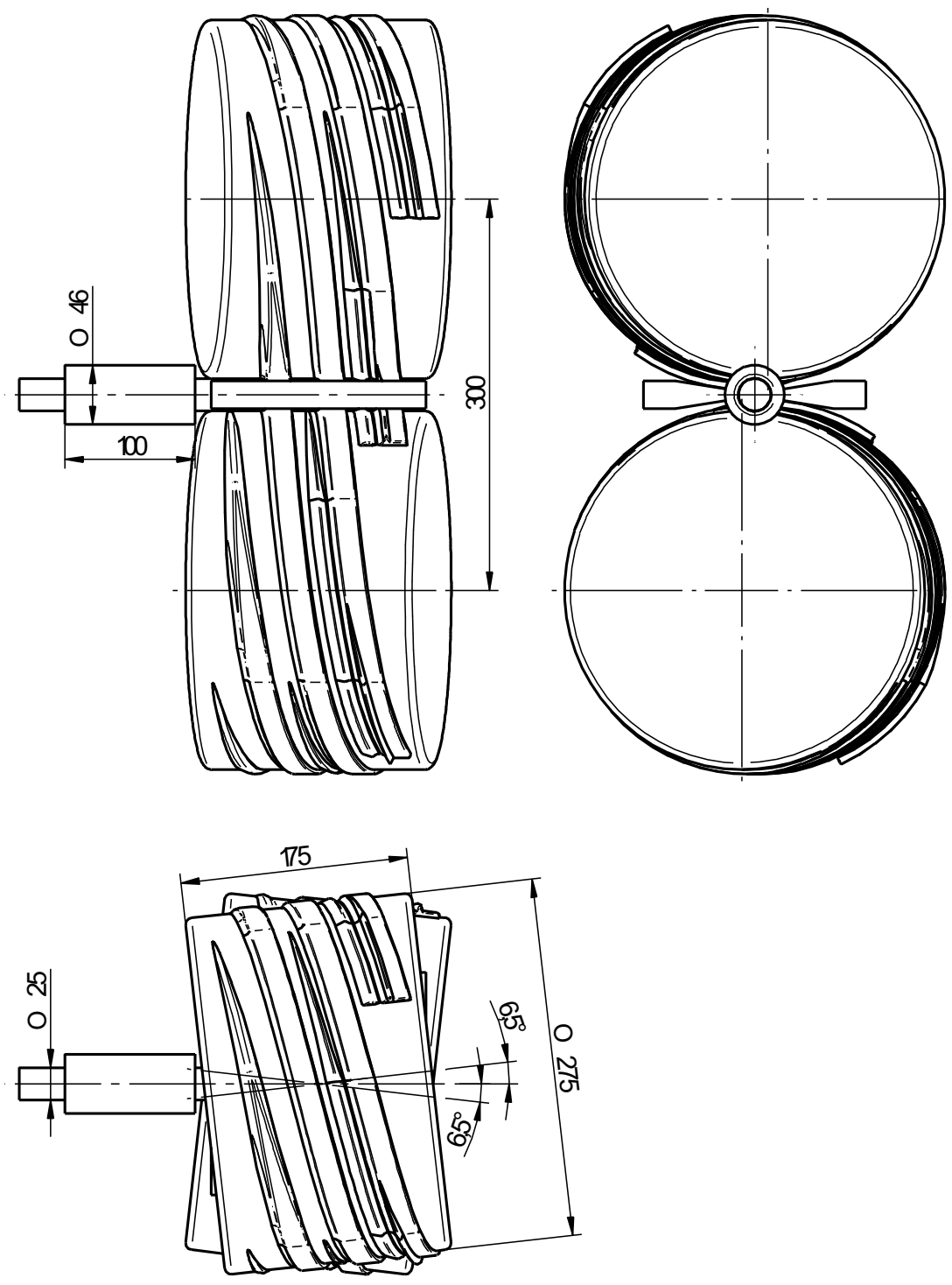

Figure 2. Schematic design of the multi-wedge helical rolling (MWHR) process for producing a workholding bolt (with selected dimensions shown in the figure)

In addition, the computations were limited either to the steady-state stage of the process or to the beginning of the forming process. Complete numerical models of the piercing process for thick-walled tubes taking into consideration thermal phenomena were constructed by several authors only in the last ten years [17-25]. The computations were performed with commercial simulation programs such as MSC. SuperForm [15, 21 23], Forge [18-20], Deform-3D [25].

Other studies were devoted to numerical analysis of elongation processes in helical rolling mills. One can mention here publications on elongation of such parts as thick-walled tubes [26-30], round ingots [31, 32] and round bimetallic bars $[33,34]$. The fact that there is a scarce number of publications on elongation processes can be attributed to long computational time, which imposes limits on the number of forming cases for analysis.

It can be observed that the smallest number of publications concerns the modeling of helical rolling process with helical rolls. Aside from the above mentioned publications by the present author [5-12], there are only few other publications available on producing shafts [35-37] and balls produced by cold rolling [38-40].

\section{Design of the MWHR process for workholding bolts}

Fig. 2 shows a schematic design of the MWHR process for producing workholding bolts using three-coil wedge rolls. Aside from the rolls, the model also consists of two guiding blades for maintaining the billet in the workspace of the rolls and a sleeve for feeding the billet into the workspace of the rolls. To make the process automatic, the rolls are twisted relative to the axis of the billet by an angle $\theta$ set to $6.5^{\circ}$.

The forming wedges are wound on the roll face with a variable pitch applied such that the material adheres to the surface of the working (lateral) wedges during the entire forming process. The spreading angle and the angle of inclination were selected intuitively based on the 


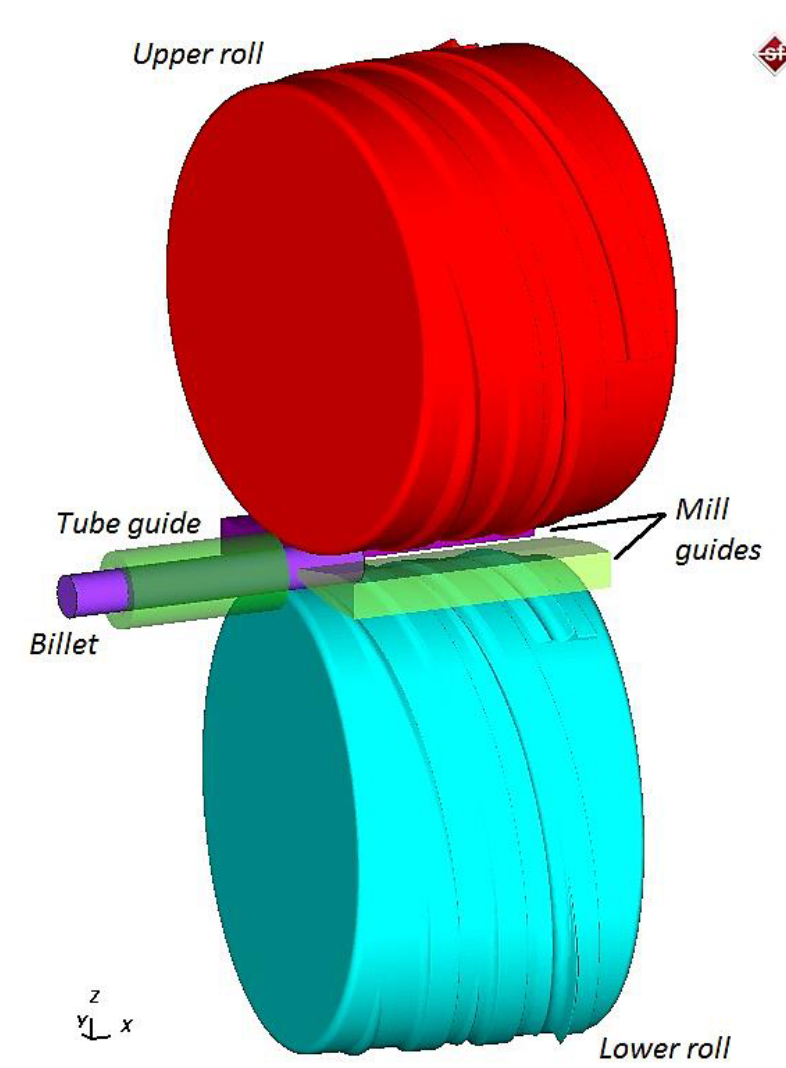

Figure 3. Geometrical model of the multi-wedge helical rolling process for producing workholding bolts

author's considerable experience in modeling of typical cross wedge rolling (CWR) processes. The wedges are located every $120^{\circ}$ on the perimeter of the rolls.

The finite element method analysis verifying the correctness of the developed solution was performed on a geometrical model of the MWHR process for workholding bolts shown in Fig. 3. The billet was assumed to be made of a corrosion-resistant steel grade $\mathrm{X} 12 \mathrm{CrNi17-12}$ and its material model (yield stress $\sigma_{\mathrm{p}}$ versus temperature $T$, effective strain $\varepsilon$ and strain rate $\dot{\varepsilon}$ ) was obtained from the material database of the applied software, i.e. Simufact.Forming v. 12. As for other parameters applied in the simulation, the billet temperature was set to $1100{ }^{\circ} \mathrm{C}$, the temperature of the rolls was $50{ }^{\circ} \mathrm{C}$, the temperature of other tools was 250 ${ }^{\circ} \mathrm{C}$, the friction factor was set to 0.9 for the rolls and to 0.4 for other tools, the material-tools heat transfer coefficient was $10 \mathrm{~kW} / \mathrm{m}^{2} \mathrm{~K}$, and the rotational speed of the rolls was $15 \mathrm{rev} / \mathrm{min}$.

The billet (with a diameter of $25 \mathrm{~mm}$ and a length of $185 \mathrm{~mm}$ ) was modeled using eight-node cubic elements, with the mesh refined in the forming zone. Due to the change of material shape during rolling, the model had to be remeshed, and the number of elements was gradually increased from 12414 at the beginning to 47659 at the end (for time $\mathrm{t}=6 \mathrm{~s}$ ), as shown in Fig. 4 .

\section{Numerical results}

The application of FEM enabled numerical verification of the developed MWHR process for producing a workholding bolt. Fig. 4 shows the changes in workpiece shape in the advanced (steady state) stage of forming after producing the first part. The developed process is highly efficient (three bolts are produced during one revolution of the rolls) and characterized by reduced material waste. One billet generates two end scraps, which means that increased workpiece length could lead to higher material efficiency. After forming, the parts are separated from one another by a helical cutter that is mounted at the end of the wedge. In the solution described in this paper, the cutter's height is decreased on purpose; in this way, the cutters only make a necking (thereby indicating where the cutting is to be made) and they do not separate the material (this would stop the numerical simulation). As a result, it was unequivocally found that the MWHR process can be used to produce parts such as workholding bolts.

Fig. 5 shows the distributions of effective strain in the axial section and on the surface of the produced part. The data given in this figure demonstrate that the strains in the cross section are not uniformly distributed. The highest strains are located at the part's surface and they gradually decrease the closer it is to the axis of the workpiece. Such a distribution of strains results from a rapid flow of the material in the tangential direction caused by the friction forces. This tangential flow is characteristic of cross and helical rolling processes. In addition, it was observed that cross sectional reduction leads to a higher effective strain

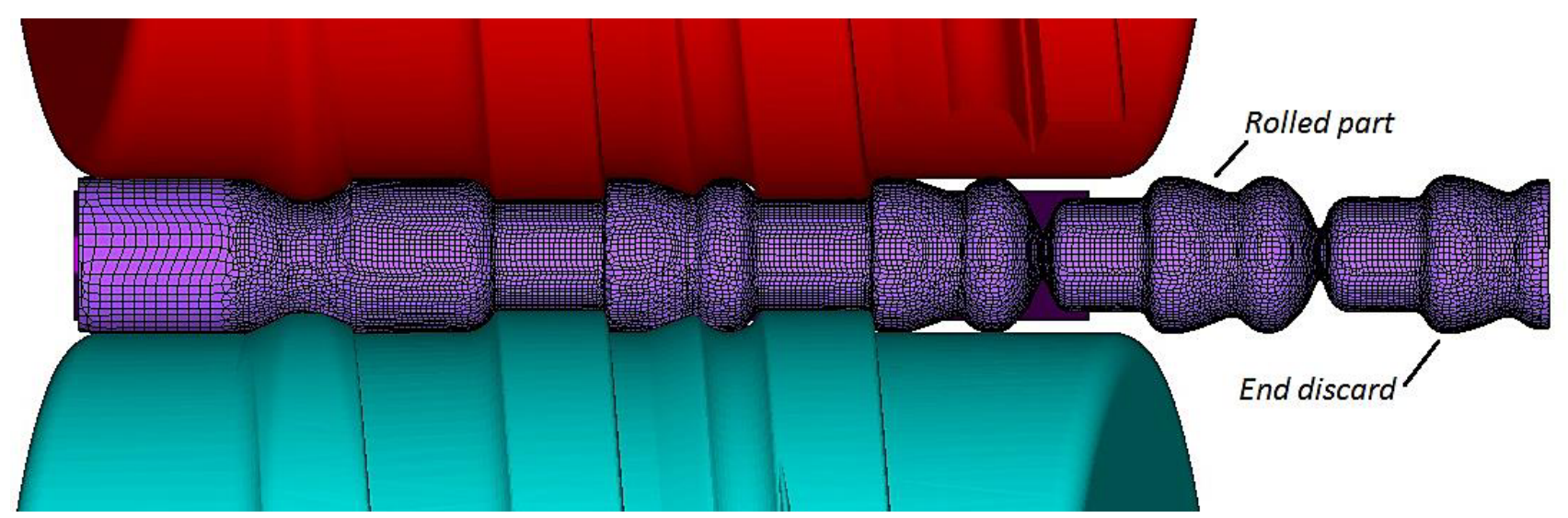

Figure 4. Workpiece after 1.5 revolution of the rolls, with division into finite elements 


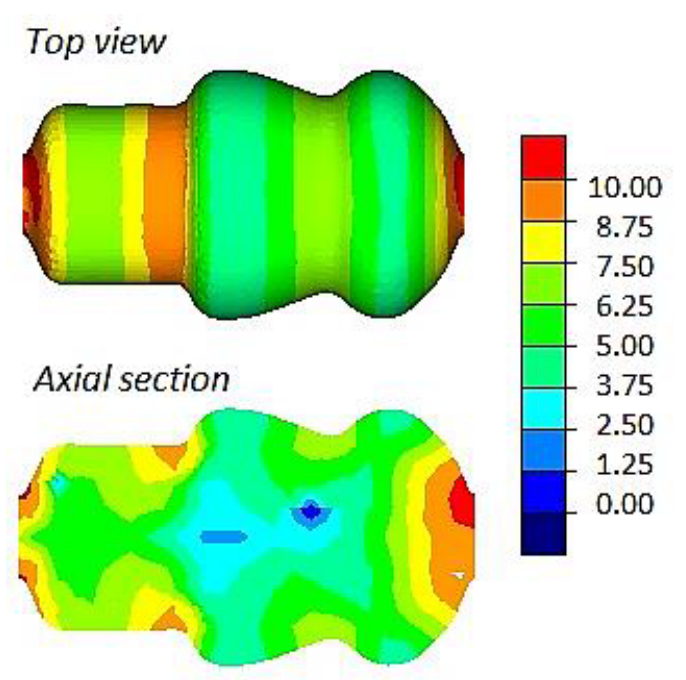

Figure 5. Distribution of effective strain in a part produced by MWHR

in the semi-finished part.

In the analyzed process, a single part is formed during 1.5 revolution of the rolls, which is equal to $6 \mathrm{~s}$. In this period of time, the material has contact with cold tools which absorb heat. At the same time, the exchange of friction work into strain work leads to generation of considerable amounts of heat, which partly compensates for heat losses resulting from the heat transfer to the tools (Fig. 6). As a consequence, the temperature of the workpiece decreases in the surface regions (up to $150^{\circ} \mathrm{C}$ ) while it increases in the region of bridges that separate individual bolts (up to $75^{\circ} \mathrm{C}$ ). It is important here that the temperature of the material is maintained during the whole forming process in a range suitable for hot metal forming processes (Fig. 7).

Interesting observations can be made with respect to

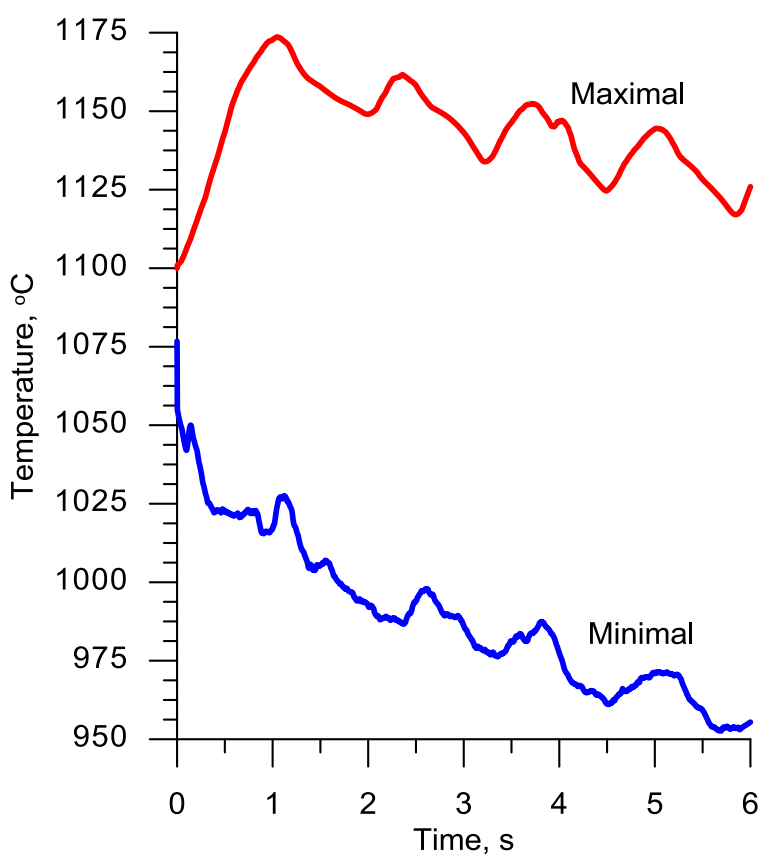

Figure 7. Maximum and minimum temperatures of the workpiece during MWHR

the distribution of the damage function (calculated in compliance with the Cockcroft-Latham criterion), shown in Fig. 8. The highest values of this function occur at the ends of the part, i.e. in the places affected by the cutters. It is in these places that material cohesion can be broken, so the bolt is separated from the rest of the material.

The application of FEM also allows us to determine distributions of force parameters during MWHR. They are illustrated in Fig. 9 (radial and tangential loads) and in Fig. 10 (torque on the roll). These distributions have a characteristic oscillatory character, which reflects the

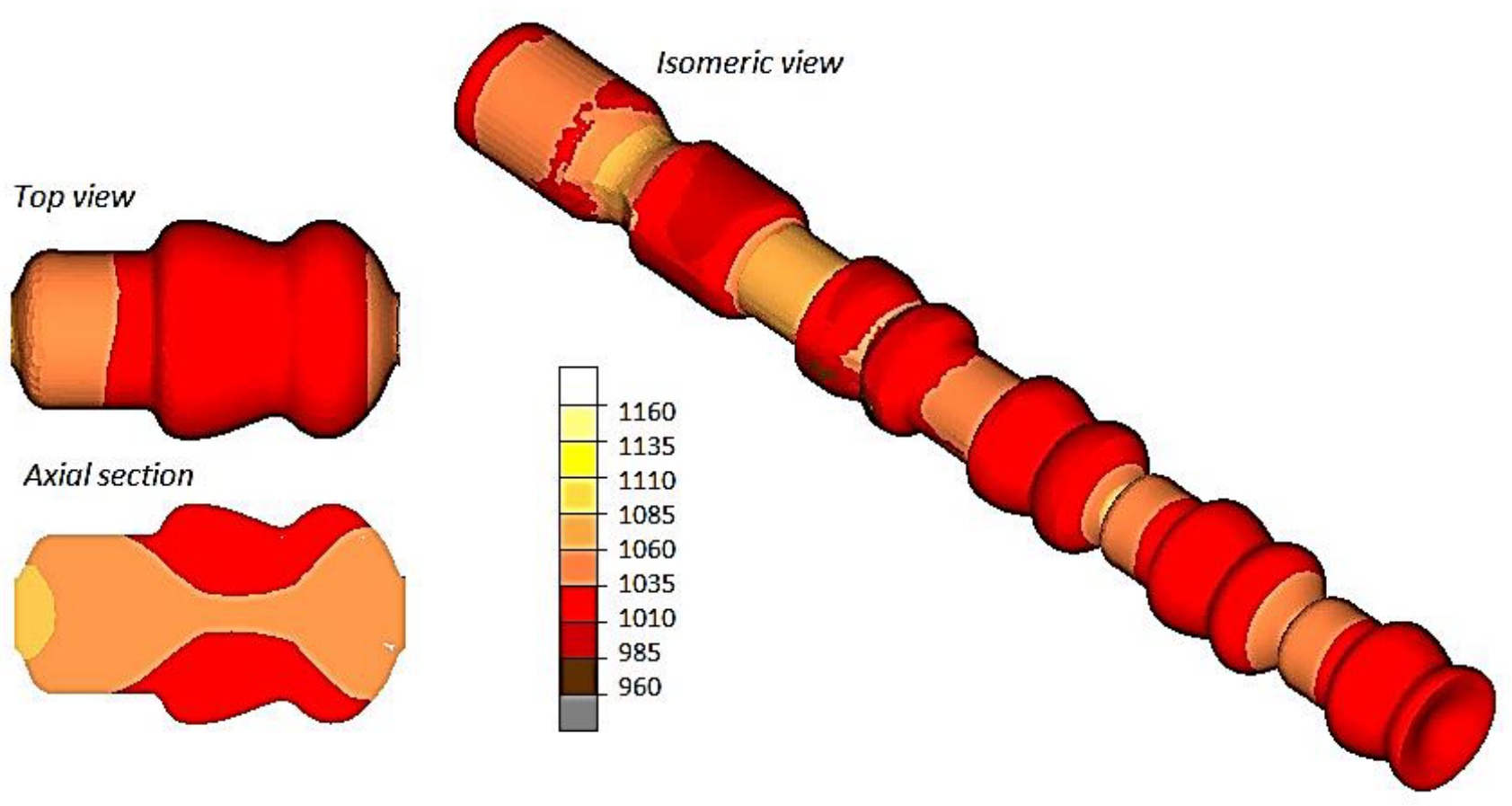

Figure 6. Distribution of temperature $\left(\right.$ in ${ }^{\circ} \mathrm{C}$ ) in a single part and in the entire semi-finished product after 1.5 revolution of the rolls 


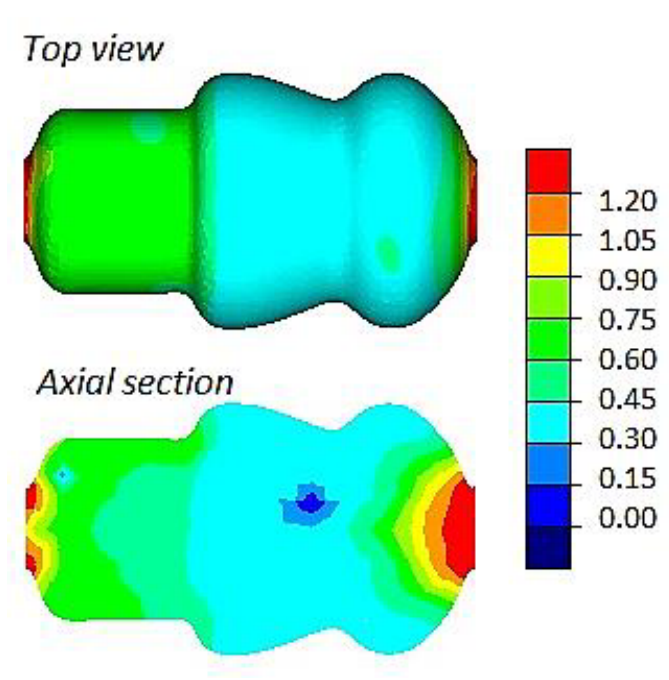

Figure 8. Distribution of the Cockcroft-Latham damage function in a part produced by MWHR

cyclical nature of the contact between the material being formed and the helical wedges. Owing to this kind of distribution of force parameters in the MWHR process, it is suggested that the process should be run using roll stands equipped with flywheels accumulating energy in the rotational motion.

\section{Conclusions}

The paper investigated the possibility of producing workholding bolts by a new process of multi-wedge helical rolling (MWHR) developed at the Lublin University of Technology. The results led to the following conclusions:

- parts such as workholding bolts can be produced by three-coil wedge rolls;

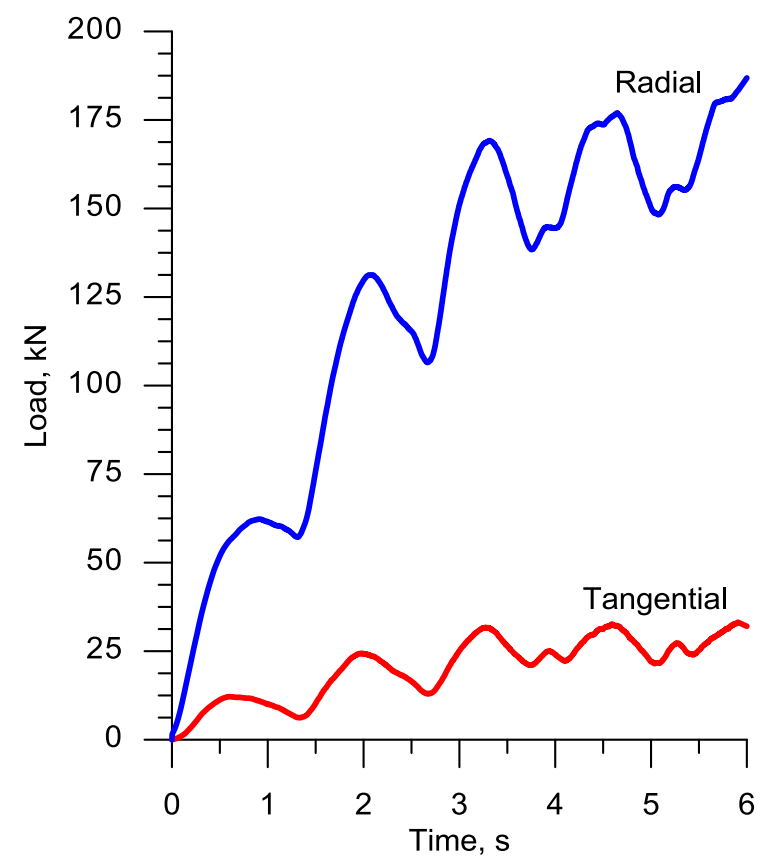

Figure 9. Distribution of loads acting on the tool in the investigated MWHR process

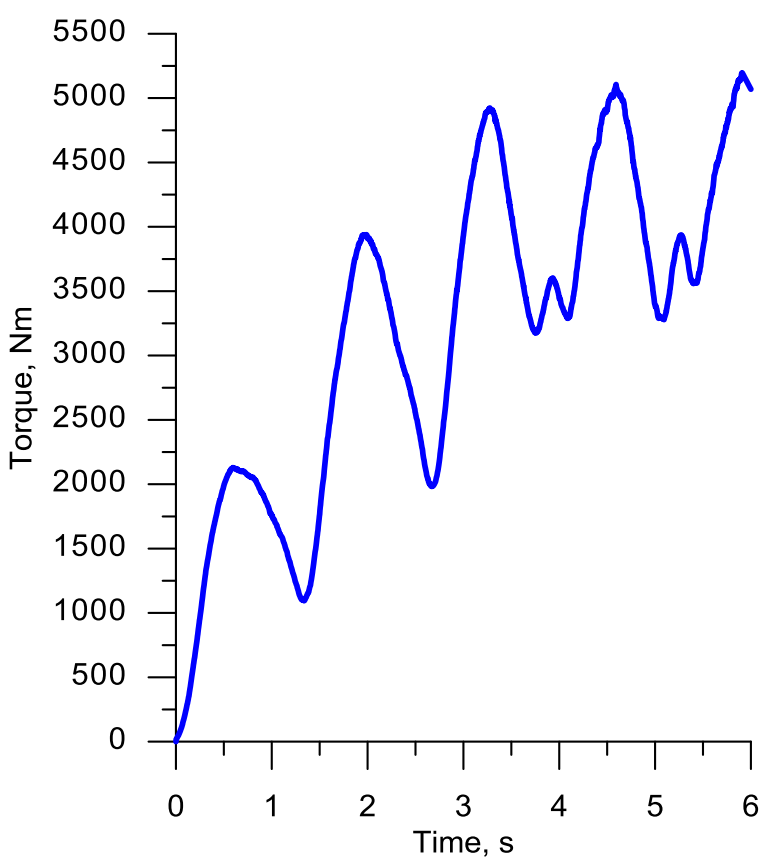

Figure 10. Distribution of torque in the investigated MWHR process

- $\quad$ strains in workholding bolts produced by MWHR are distributed in a way that is typical of cross and helical rolling processes;

- the temperature of the investigated workholding bolt material is maintained in a range that is suitable for hot metal forming;

- $\quad$ workholding bolts produced by MWHR are free from internal cracking, which is often the case with parts produced by helical rolling (the so-called Mannesmann effect);

- force parameters in MWHR are distributed in a characteristic oscillatory manner, which reflects the nature of this forming process in which the wedges cyclically cut in the material being formed;

- it is necessary to construct a laboratory stand that will enable experimental verification of the described MWHR process.

\section{Acknowledgements}

This research was made under agreement no. INNOTECH-K3/IN3/12/226286/NCBR/14 on conducting and financing projects under the "INNOTECH" program, IN-TECH program path.

\section{References}

1. K. Lange, Handbook of Metal Forming (Ed. McGraw-Hill Book Company, 1985)

2. Z. Pater, G. Samołyk, Podstawy obróbki plastycznej metali (Ed. Lublin Univ. of Technology, Lublin, 2013)

3. Z. Pater, J. Tomczak, Walcowanie poprzecznoklinowe kul (Ed. Lublin Univ. of Technology, Lublin, 2012) 
4. Z. Pater, J. Tomczak, Walcowanie śrubowe kul do młynów kulowych (Ed. Lublin Univ. of Technology, Lublin, 2012)

5. Z. Pater Z., J. Tomczak, J. Kazanecki, J. Iron Steel Res. Int. (2012) Spec. Ed. Metal Forming 2012, 7982

6. Z. Pater, Int. J. Mater. Prod. Tec. 47, 1/2/3/4 (2013)

7. Z. Pater, J. Tomczak, J. Bartnicki, M.R. Lovell, P.L. Menezes, Int. J. Mach. Tool. Manu. 67 (2013)

8. J. Tomczak, Z. Pater, J. Bartnicki, Arch. Metall. Mater. 58, 4 (2013)

9. Z. Pater, J. Tomczak, T. Bulzak, Mechanik 86, 11 (2013)

10. Z. Pater, Key Eng. Mat. 622-623 (2014)

11. Z. Pater, A. Tofil, Hutnik - Wiadomości Hutnicze 80, 10 (2013)

12. Z. Pater, Metalurgija 53, 4 (2014)

13. S. Urbański, J. Kazanecki, J. Mater. Process. Tech. 45 (1994)

14. J. Pietsh, P. Thievien, MPT International 2 (2003)

15. E. Ceretti, C. Giardini, A. Attanasio, F. Brisotto, G. Capoferri, TPT, March/April (2004)

16. K. Komori, Int. J. Mech. Sci. 47 (2005)

17. Z. Pater, J. Kazanecki, J. Bartnicki, J. Mater. Process. Tech. 177 (2006)

18. R. Pschera, J. Klarner, C. Sommitsch, BHM 152, 7 (2007)

19. Y. Chastel, A. Diop, S. Fanini, P.P. Bouchard, K. Mocellin, Int. J. Mater. Form, Suppl. 1 (2008)

20. A. Ghiotti, S. Fanini, S. Bruschi, P.F. Bariani, CIRP Ann-Manuf. Techn. 58 (2009)

21. L. Lu, F. Wang, Z. Wang, G. Zhu, X. Zhang, J. Iron Steel Res. Int. 18, 7 (2011)
22. L. Lu, Z. Wang, F. Wang, G. Zhu, X. Zhang, J. Shanghai Jiaotong Univ. (Sci.) 16, 3 (2011)

23. Z. Pater, J. Bartnicki, J. Kazanecki, Metalurgija 51, 4 (2012)

24. Z. Pater, J. Kazanecki, Arch. Metall. Mater. 58, 3 (2013)

25. F. Wang, Y. Shuang, J. Hu, Q. Wang, J. Sun, J. Mater. Process. Tech. 214 (2014)

26. Z. Malinowski., J. Kazanecki, S. Urbański, J. Mater. Process. Tech. 60 (1996)

27. R.J. Montecinos, E.S. Arauco, J. Mater. Process. Tech. 95 (1999)

28. Z. Pater, J. Kazanecki, Hutnik - Wiadomości Hutnicze 74, 9 (2007)

29. B. Li, S.H. Zhang, G.L. Zhang, H.Q. Zhang, J. Mater. Process. Tech. 205 (2008)

30. F. Wang, Y. Shuang, J. Hu, Q. Wang, J. Sun, J. Mater. Process. Tech. 214 (2014)

31. E.I. Panov, Metallurgist 48, 1-2 (2004)

32. E.I. Panov, Metallurgist 48, 3-4 (2004)

33. S. Sawicki, P. Szota, H. Dyja, AMSE 32, 1 (2008)

34. S. Sawicki, P. Szota, S. Mróz, A. Stefanik, H. Dyja, Obróbka Plastyczna Metali 20, 1 (2009)

35. Y. Kang, Z. Hu, J. Liu, C. Yang, H. Du, J. Mater. Sci. Technol. 19, Suppl. 1 (2003)

36. G. Fang, P. Zeng, J. Mater. Sci. Technol. 19, Suppl. 1 (2003)

37. H. Yang, L. Zhang, Z. Hu, Adv. Mat. Res. 538-541 (2012)

38. X. Shi, B. Wang, Mater. Sci. Forum 704-705 (2012)

39. X. Ren, Y. Liu, AMM 117-119 (2012)

40. Q. Cao, L. Hua, D. Qian, J. Cent. South Univ. 22 (2015) 